\title{
Investigating the Cellular and Molecular Mechanisms of Wound Healing in Xenopus Oocytes and Embryos
}

\author{
Jingjing $\mathrm{Li}^{1}$ and Enrique Amaya ${ }^{2,3}$ \\ ${ }^{1}$ Department of Craniofacial Development and Stem Cell Biology, Dental Institute, King's College London, \\ London SE1 9RT, United Kingdom; ${ }^{2}$ Division of Cell Matrix Biology \& Regenerative Medicine, Faculty of Life \\ Sciences, The University of Manchester, Manchester M13 9PT, United Kingdom
}

The African clawed frog Xenopus has remarkable capacities to heal wounds rapidly and to regenerate complex tissues. Because of its experimental tractability, studies using Xenopus oocytes, embryos, and larvae have contributed extensively to our understanding of the molecular and cellular mechanisms underpinning wound healing and tissue regeneration. In this protocol, we describe wound-healing assays following mechanical or laser injuries of oocytes and multicellular epithelia in Xenopus laevis embryos. We also explain how to perform assays aimed at investigating the cellular and molecular events during wound healing, including gene knockdown and overexpression experiments. In the latter assays, we explore the use of biochemical pull-down assays to investigate the activity of Rho GTPases, as well as the injection of mRNAs encoding fluorescent proteins or probes, followed by quantitative confocal image analyses to assay the dynamics of cytoskeletal components and their regulators.

It is essential that you consult the appropriate Material Safety Data Sheets and your institution's Environmental Health and Safety Office for proper handling of equipment and hazardous materials used in this protocol.

RECIPES: Please see the end of this protocol for recipes indicated by $<R>$. Additional recipes can be found online at http://cshprotocols.cshlp.org/site/recipes.

\section{Reagents}

Agarose

Antibodies, anti-Cdc42 (Cell Signaling Technology 2462) (for GST pull-down assays only) Antibodies, anti-Rac1/2/3 (Cell Signaling Technology 2465) (for GST pull-down assays only) Antibodies, anti-RhoA (Santa Cruz Biotechnology SC-179) (for GST pull-down assays only) Bovine serum albumin (BSA)

Constructs (optional; see Steps 1, 7.ii, 7.iv, 11)

Embryos can be injected with moesin-gfp to observe actin dynamics (Li et al. 2013), gfp- $\alpha$-tubulin to observe microtubule dynamics (Woolner and Papalopulu 2012), GEM-GECO or C2-mrfp to observe calcium dynamics (Clark et al. 2009; Soto et al. 2013), or gfp/mcherry-caax to label the plasma membrane and thus outline the cell

\footnotetext{
${ }^{3}$ Correspondence: enrique.amaya@manchester.ac.uk

From the Xenopus collection, edited by Hazel L. Sive.

(C) 2019 Cold Spring Harbor Laboratory Press

Cite this protocol as Cold Spring Harb Protoc; doi:10.1101/pdb.prot100982
} 


\section{Equipment}

Centrifuge, refrigerated (for GST pull-down assays only)

Coverslips

Forceps, fine (Dumont \#5)

Imaging chamber, steel (optional; for laser wounding experiments [Fig. 1C,D])

Microscope, confocal, equipped with a MicroPoint pulsed nitrogen-pumped ablation dye laser (e.g., Laser Science, Inc.)

Microscope, dissection, equipped with LED illumination and a $10 \times-75 \times$ zoom range

Nutator (for GST pull-down assays only)

Petri dishes, with or without glass bottom

Tissue homogenizer (for GST pull-down assays only)

Tubes, microcentrifuge, 1.5-mL (for GST pull-down assays only)

Vortexer (for GST pull-down assays only)

Additional reagents and equipment for western blotting (for GST pull-down assays only)

\section{METHOD}

\section{Mechanical Wounding Assays Using Xenopus Embryonic Epithelia}

1. If gain- or loss-of-function experiments are desired, inject 1-2-cell stage embryos with antisense morpholino oligonucleotides or in-vitro-transcribed mRNAs targeting or encoding the gene products of interest, respectively, before raising the embryos to the blastula or tailbud stages.

2. Culture embryos in $0.1 \times \mathrm{MMR}$ at either room temperature or $16^{\circ} \mathrm{C}$ until the blastula or tailbud stages.

3. Transfer embryos to $75 \%(\mathrm{v} / \mathrm{v})$ NAM containing $0.2 \%$ BSA in an agarose dish. For drug treatment assays, preincubate embryos for 30 min before wounding experiments.

4. Perform epithelial wounding experiments at the desired stage of development:

When regions of the epithelium are removed, it is common to remove some of the yolk cells under the skin. This should have minimal effect on the experiment. However, the size of the wound in Steps 4.ii and 4.iv should be kept as consistent as possible to ensure consistent results between replicates and reliable comparisons between different treatments. 
A

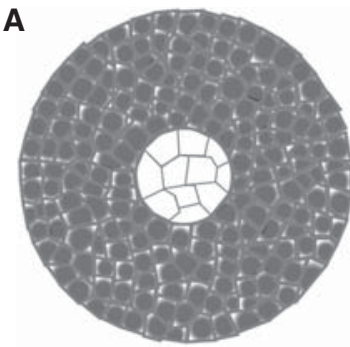

$\mathbf{E}$
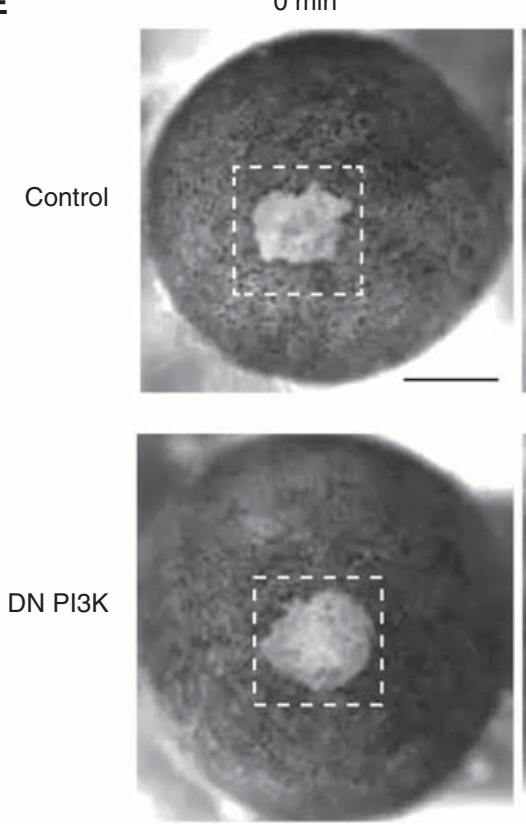

B

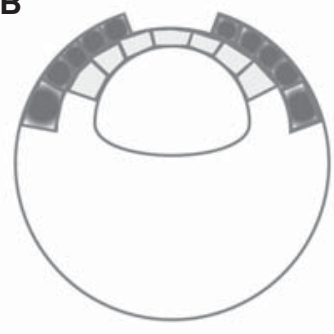

C

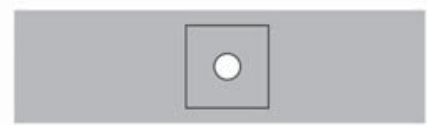

D

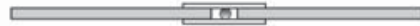

$15 \min$
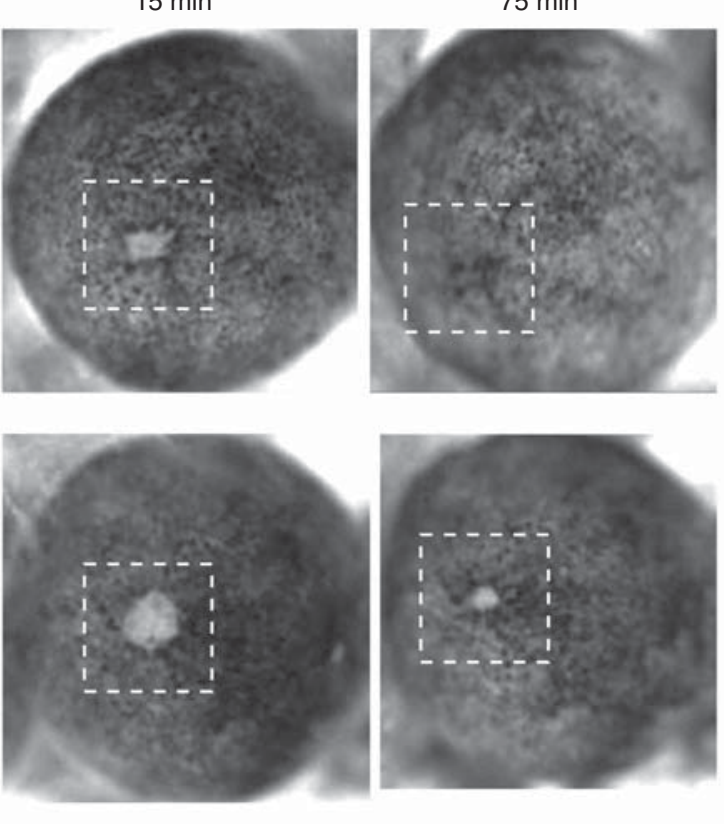

FIGURE 1. Wounding and observation of embryonic epithelium. (A) Top view of a superficial wound on the animal side of a blastula embryo. Pigmented cells are of the superficial layer, and nonpigmented cells are of the deep layer, which is kept intact in the experiment. $(B)$ Transverse side view of a superficial wound on a blastula embryo. (C) Selfmade imaging chamber for laser wounding and observation. The big (gray) slide is made of steel, with a hole in the middle. (D) Side view of the chamber, with an embryo mounted inside the hole and sealed from both sides with coverslips. (E) Sample pictures of wound healing in control and dominant-negative (DN) PI3K-overexpressing blastula stage embryos. Note that, although control wounds heal completely by 75 min postinjury, DN PI3K-expressing wounds maintain incompletely healed wounds at 75 min postinjury. Wounded areas are highlighted in dashed squares. Scale bar: $200 \mu \mathrm{m}$.

\section{For Blastula Stage Epithelial Wounding Experiments}

i. Use clean fine forceps to remove the vitelline membranes of a Stage 8 embryo. Approach from the vegetal (i.e., unpigmented) side of the embryo to limit damage to the animal (i.e., pigmented) side.

ii. Carefully remove a desired area of the superficial outer (pigmented) layer of the animal side (e.g., an 8-10 cell diameter area), leaving the deep (unpigmented or lightly pigmented) layer intact (Fig. 1A,B).

\section{For Tailbud Stage Epithelial Wounding Experiments}

iii. Use clean fine forceps to remove the vitelline membrane from the embryo.

iv. Remove, pinch or puncture a desired area of the epithelium in the flank of the embryo (e.g., one-third the length of the trunk of the embryo). 
5. Leave embryos in 75\% NAM throughout the experiment.

6. Image the embryos:

\section{To Assess the Overall Effect of a Gene or a Drug on Wound Healing}

i. Observe wounded embryos using either a dissection microscope, or low magnification (e.g., $10 \times-20 \times$ ) using a confocal microscope. Image every $20 \mathrm{~min}$.

Completion of wound closure takes a few hours (examples of successful and incomplete healing are shown in Fig. 1E). Wound closure under a stereoscope can be measured by outlining the leading edge of the epithelium (Fig. 1E).

See Troubleshooting.

\section{To Observe the More Rapid Dynamics of the Cytoskeleton or Signaling Events}

ii. Image every 2 min using a confocal microscope equipped with a $60 \times$ objective. Depending on the process under investigation, images might need to be taken more or less frequently to capture its dynamic nature.

Laser Wounding Assays in Xenopus Oocytes and Embryonic Epithelia

7. Prepare the experimental tissues:

\section{For Oocyte Laser Wounding Assays}

i. Prepare oocytes as described in Sive et al. (2000).

ii. Inject morpholino or mRNAs as desired.

iii. Culture the oocytes at $16^{\circ} \mathrm{C}$ until needed.

\section{For Embryonic Epithelial Laser Wounding Assays}

iv. Inject embryos with morpholinos or mRNAs at the 1-2 cell stage.

v. Culture until Stage 9 in $0.1 \times$ MMR.

8. Mount oocytes or embryos in a glass bottom dish or coverslip-sealed imaging chamber (Fig. 1C, D) in $75 \%$ NAM. Fit the dish or imaging chamber on a confocal stage.

9. Make laser wounds on the surface of the oocyte or the embryo.

A possible combination of pulsed laser settings using the MicroPoint laser to ablate the tissue is: $561 \mathrm{~nm}$ wavelength, power 40 and pulse 10. The user is advised to adjust the settings and equipment to fulfill their specific experimental requirements.

10. Observe and record the wound healing process immediately postwounding.

Take images as frequently as possible, being conscious to ensure minimal photo-damage while capturing the dynamics of the proteins or signals under investigation.

GST Pull-Down to Quantify Activation of Small Rho GTPases: Rac, Cdc42, and RhoA

11. Inject Xenopus embryos at the 1-2-cell stage with desired mRNAs:

\section{To Detect Rac1 and Cdc42 Activities}

i. Inject 500 pg mRNA of pak1-gst.

\section{To Detect RhoA Activity}

ii. Coinject 500 pg mRNA of egfp-rhotekinGBD and 125 pg rhoa mRNA.

12. Grow embryos to Stage 8 or 9 in $0.1 \times$ MMR. 
13. Resuspend and transfer $300 \mu \mathrm{L}$ Glutathione Sepharose beads into $1.5 \mathrm{~mL}$ microcentrifuge tubes.

14. Centrifuge at $1000 \mathrm{~g}$ for $30 \mathrm{sec}$ at $4^{\circ} \mathrm{C}$. Remove the upper aqueous phase without disturbing the bead pellet.

15. Wash the beads with $300 \mu \mathrm{L}$ GST binding buffer three times at the same centrifugation speed and temperature.

16. Resuspend the beads in $150 \mu \mathrm{L}$ of GST binding buffer. Place on ice until use.

17. Wound Stage 8 or 9 embryos with forceps in $75 \%$ NAM.

18. Collect 30-50 embryos per condition or time point in $1.5 \mathrm{~mL}$ microcentrifuge tubes. Remove as much liquid as possible. Place the tubes on ice.

19. Homogenize each tube of embryos in $500 \mu \mathrm{L}$ freshly prepared and prechilled embryo lysis buffer.

20. Centrifuge at maximum speed (e.g., $>16,000 \mathrm{~g}$ ) for $15 \mathrm{~min}$ at $4^{\circ} \mathrm{C}$.

21. Transfer the supernatant to another prechilled microcentrifuge tube. Add $200 \mu \mathrm{L}$ prechilled Freon 113 to each tube. Vortex for $15 \mathrm{sec}$.

22. Centrifuge at maximum speed for $10 \mathrm{~min}$ at $4^{\circ} \mathrm{C}$.

23. Transfer the upper aqueous phase to a new microcentrifuge tube ( $\sim 450 \mu \mathrm{L}$ total volume). Withdraw and reserve $5 \%$ of this volume (i.e., $\sim 9 \mu \mathrm{L}$ ) as input.

24. Add an equal volume ( $450 \mu \mathrm{L})$ of GST binding buffer and $50 \mu \mathrm{L}$ of prewashed beads (from Step 16) to each tube. Incubate on an end-to-end nutator for $30 \mathrm{~min}$ (for Racl and Cdc42) or $1 \mathrm{~h}$ (for RhoA) at $4^{\circ} \mathrm{C}$.

25. Centrifuge the tubes at $1000 \mathrm{~g}$ for $30 \mathrm{sec}$ at $4^{\circ} \mathrm{C}$. Remove the buffer.

26. Wash the beads once with $500 \mu \mathrm{L}$ precooled GST binding buffer, and twice with precooled GST wash buffer. To mix, gently invert the tubes 3-4 times; do not pipette. Centrifuge at $1000 \mathrm{~g}$ for $30 \mathrm{sec}$ at $4^{\circ} \mathrm{C}$ between each wash.

27. Detect and measure levels of active Rac, Cdc42, and RhoA using Western blot as described in Li et al. (2013).

Problem (Step 6.i): The leading edge of the wound is difficult to locate.

Solution: Normally, the leading edge should be clear to see because of the color difference between the two epithelial layers. If it is difficult to locate the edge, embryos can be fixed at the end of experiments and stained using phalloidin. For confocal imaging, embryos can be injected with mRNAs of proteins that either localize to the cell membrane or bind to F-actin; both outline the leading edge during wound healing.

\section{DISCUSSION}

We present three protocols to assay wound healing in Xenopus oocytes or embryos: mechanical wounding in macroscale, and laser wounding and GST pull-down assays at the cellular and molecular level. Of the three, mechanical wounding and observation (Steps 1-6) is the most accessible. When combined with gene knockdown/knockout or chemical treatment, it provides a rapid and robust assessment whether a certain gene, protein, or signaling pathway is involved in wound healing (Li et al. 2013, 2016; Soto et al. 2013). Nonetheless, it does require some practice to make the size and depth of wounds consistent, which can affect the speed and quality of healing. 
Laser wounding (Steps 7-10) has two major advantages. First, because the wounding laser is often mounted on (or a part of) a confocal or multiphoton system, it is easy to injure and then immediately image using the same system. Second, the observation of the cellular and molecular events can be started seconds or even milliseconds postwounding, which cannot be achieved after mechanical wounding. For this reason, laser wounding has become the method of choice in a variety of experiments to assess the molecular and cellular bases of Xenopus wound healing (Clark et al. 2009; Burkel et al. 2012; Soto et al. 2013; Davenport et al. 2016). Specifically, membrane and cytoskeletal dynamics - and how they are regulated by small Rho GTPases and their effectors near the wound edge-were studied using a single-cell laser-wounding model (Burkel et al. 2012; Davenport et al. 2016). Multicellular cytoskeletal networks and signal propagation to mobilize a sheet of epithelium in multicellular wound healing were studied using an embryonic wounding model (Clark et al. 2009; Soto et al. 2013). On the other hand, the challenge of this protocol is to maintain normal tissue growth or vitality over time, particularly in an experiment lasting hours. Therefore, tests and calibrations of tissue health should always be performed before an experiment.

In the past decade, fluorescence resonance energy transfer (FRET)-based tools to measure activation of small Rho GTPases have been well developed (Fritz and Pertz 2016), especially in cultured cells (Santiago-Medina et al. 2012). However, the use of FRET tools in Xenopus embryo is still limited (Yamashita et al. 2016), making biochemical approaches such as the active Rho GST pull-down assays (Steps 11-27) valid and powerful methods to examine the dynamics of these signaling molecules. Also, because the readout of this assay is based on a collection of embryos, individual effects are reduced to a minimum, giving a more robust measurement of the activity of the detected molecules. A current limitation of this protocol is the limited availability of antibodies in Xenopus; thus, detection of endogenous proteins pulled down is not always possible. In such cases, overexpression of tagged target proteins can be used as an alternative for the measurements.

\section{GST Binding Buffer}

$25 \mathrm{~mm}$ Tris-HCl, $\mathrm{pH} 7.5$

$30 \mathrm{~mm} \mathrm{MgCl}_{2}$

$40 \mathrm{~mm} \mathrm{NaCl}$

1 mu dithiothreitol

$0.5 \%$ Nonidet P-40

cOmplete, Mini Protease Inhibitor ( 1 tablet/10 mL; Roche 04693124001)

PhosStop Phosphatase Inhibitor ( 1 tablet/10 mL; Roche PHOSS-RO)

Prepare fresh. Keep on ice until use.

\section{GST Wash Buffer}

25 mм Tris- $\mathrm{HCl}, \mathrm{pH} 7.5$

$30 \mathrm{~mm} \mathrm{MgCl}_{2}$

$40 \mathrm{~mm} \mathrm{NaCl}$

Prepare fresh. Keep on ice until use. 
Marc's Modified Ringer's (MMR) (10x)

$20 \mathrm{~mm} \mathrm{CaCl}_{2}$

$50 \mathrm{~mm}$ HEPES (pH 7.5)

$20 \mathrm{~mm} \mathrm{KCl}$

$10 \mathrm{~mm} \mathrm{MgCl}_{2}$

$1 \mathrm{M} \mathrm{NaCl}$

Adjust $\mathrm{pH}$ with $\mathrm{NaOH}$ to 7.5. Sterilize by autoclaving. Store at room temperature.

\section{Normal Amphibian Medium (NAM) (10x)}

\section{$1.1 \mathrm{M} \mathrm{NaCl}$}

$20 \mathrm{~mm}$ sodium phosphate $(\mathrm{pH} 7.4)$

$20 \mathrm{~mm} \mathrm{KCl}$

$10 \mathrm{~mm} \mathrm{Ca}\left(\mathrm{NO}_{3}\right)_{2}$

$10 \mathrm{~mm} \mathrm{MgSO}_{4}$

$10 \mathrm{~mm} \mathrm{NaHCO}_{3}$

$1 \mathrm{~mm}$ EDTA

Store at room temperature.

\section{Xenopus Embryo Lysis Buffer}

$50 \mathrm{~mm}$ Tris- $\mathrm{HCl}$ (pH 7.5)

$100 \mathrm{~mm} \mathrm{NaCl}$

$10 \mathrm{mM} \mathrm{MgCl}_{2}$

$1 \mathrm{~mm}$ dithiothreitol

$5 \%$ glycerol

$1 \%$ Nonidet P-40

cOmplete, Mini Protease Inhibitor (1 tablet/10 mL; Roche 4693124001)

PhosStop Phosphatase Inhibitor (1 tablet/10 mL; Roche PHOSS-RO)

Prepare fresh. Keep on ice until use.

\section{REFERENCES}

Burkel BM, Benink HA, Vaughan EM, Dassow von G, Bement WM. 2012. A Rho GTPase signal treadmill backs a contractile array. Dev Cell 23: 384-396.

Clark AG, Miller AL, Vaughan E, Yu H-YE, Penkert R, Bement WM. 2009. Integration of single and multicellular wound responses. Curr Biol 19: 1389-1395.

Davenport NR, Sonnemann KJ, Eliceiri KW, Bement WM. 2016. Membrane dynamics during cellular wound repair. Mol Biol Cell 27: 2272-2285.

Fritz RD, Pertz O. 2016. The dynamics of spatio-temporal Rho GTPase signaling: Formation of signaling patterns. F1000Res 5: 749.

Li J, Zhang S, Soto X, Woolner S, Amaya E. 2013. ERK and phosphoinositide 3-kinase temporally coordinate different modes of actin-based motility during embryonic wound healing. J Cell Sci 126: 5005-5017.

Li J, Zhang S, Amaya E. 2016. The cellular and molecular mechanisms of tissue repair and regeneration as revealed by studies in Xenopus. Regeneration (Oxf) 3: 198-208.
Santiago-Medina M, Myers JP, Gomez TM. 2012. Imaging adhesion and signaling dynamics in Xenopus laevis growth cones. Dev Neurobiol 72: 585-599.

Sive HL, Grainger RM, Harland RM. 2000. Early development of Xenopus laevis: A laboratory manual. Cold Spring Harbor Laboratory Press, Cold Spring Harbor, NY.

Soto X, Li J, Lea R, Dubaissi E, Papalopulu N, Amaya E. 2013. Inositol kinase and its product accelerate wound healing by modulating calcium levels, Rho GTPases, and F-actin assembly. Proc Natl Acad Sci 110: 11029-11034.

Woolner S, Papalopulu N. 2012. Spindle position in symmetric cell divisions during epiboly is controlled by opposing and dynamic apicobasal forces. Dev Cell 22: 775-787.

Yamashita S, Tsuboi T, Ishinabe N, Kitaguchi T, Michiue T. 2016. Wide and high resolution tension measurement using FRET in embryo. Sci Rep 6: 28535. 


\section{Investigating the Cellular and Molecular Mechanisms of Wound Healing in Xenopus Oocytes and Embryos}

Jingjing Li and Enrique Amaya

Cold Spring Harb Protoc; doi: 10.1101/pdb.prot100982 originally published online June 12, 2018

\begin{tabular}{rc}
$\begin{array}{r}\text { Email Alerting } \\
\text { Service }\end{array}$ & Receive free email alerts when new articles cite this article - click here. \\
\hline $\begin{array}{c}\text { Subject } \\
\text { Categories }\end{array}$ & $\begin{array}{c}\text { Browse articles on similar topics from Cold Spring Harbor Protocols. } \\
\text { Confocal Microscopy (114 articles) } \\
\text { Developmental Biology (728 articles) } \\
\text { Imaging Development (255 articles) } \\
\text { In Vivo Imaging (334 articles) } \\
\text { In Vivo Imaging, general (168 articles) } \\
\text { Labeling for Imaging (339 articles) } \\
\text { Video Imaging / Time Lapse Imaging (171 articles) } \\
\text { Xenopus (210 articles) }\end{array}$ \\
\hline
\end{tabular}

